\title{
Bariatric surgery results in restoration of physiological plasma levels of pentraxine-3
}

\author{
ALESSANDRO F. TONIAL ${ }^{1}$, RENATO NISIHARA ${ }^{2,3}$, PAULO A.N. NASSIF ${ }^{1,2}$, SOFIA I. MUNHOZ ${ }^{2}$, \\ ALEX G. CORTINA ${ }^{2}$, JÚliA S.C. GOBETTI ${ }^{2}$ and THELMA SKARE ${ }^{1,2}$ \\ ${ }^{1}$ Medical Research Institute, Evangelical Mackenzie University; \\ ${ }^{2}$ Department of Medicine, Mackenzie Evangelical School of Medicine Paraná; \\ ${ }^{3}$ Department of Medicine, Positivo University, Curitiba, Paraná 80730-000, Brazil
}

Received August 21, 2019; Accepted November 10, 2019

DOI: $10.3892 /$ br.2019.1264

\begin{abstract}
Pentraxine-3 (PTX3) is a member of the humoral innate immune system and serves a role in protection against infections, inflammation control and matrix deposition. The aim of the present study was to measure the PTX3 levels in obese patients and its association with glycemic and lipid profiles, and to analyze the effects of weight loss provided by bariatric surgery in serum PTX3 levels. PTX3 was measured in 84 obese patients whom underwent bariatric surgery and 94 healthy controls. Lipid and glycemic profiles were determined using a clinical chemistry analyzer, and PTX3 levels were measured in patients prior to and following bariatric surgery using ELISA. PTX3 levels prior to surgery were significantly lower compared with the normal controls (median of $0.10 \mathrm{vs} .0 .80 \mathrm{ng} / \mathrm{ml} ; \mathrm{P}<0.0001$ ). Following surgery, the median weight loss was $33.1 \mathrm{~kg}$, and the median PTX3 levels were significantly increased to $1.45 \mathrm{ng} / \mathrm{ml}$ compared with pre-surgery levels $(\mathrm{P}<0.001)$ and did not differ significantly from the control group levels $(\mathrm{P}=0.10)$. There were no correlations between PTX3 levels and total cholesterol, HDL and LDL, fasting glycemia, HbAlc and basal insulin levels. A significant positive correlation was observed between PTX3 levels and triglycerides levels in the post-operative period $(\mathrm{Q}=0.26, \mathrm{P}=0.01)$. In conclusion, obese patients had lower levels of PTX3 compared with the control patients, and the levels were restored to physiological levels following bariatric surgery which may be associated with the weight loss.
\end{abstract}

\section{Introduction}

Pentraxin-3 (PTX3) is a long pentraxin identified in early 1990s that differs from short pentraxins, such as $\mathrm{C}$ reactive

Correspondence to: Professor Renato Nisihara, Department of Medicine, Mackenzie Evangelical School of Medicine Paraná, 2770 Rua Padre Anchieta, Curitiba, Paraná 80730-000, Brazil

E-mail: renatonisihara@up.edu.br

Key words: obesity, bariatric surgery, inflammation, pentraxine-3 protein (CRP) and serum amyloid A, in gene organization, ligand binding abilities and the inducing stimuli (1). Similar to the other pentraxins, PTX3 is a member of the humoral innate immune system and serves a role in protection against infections $(1,2)$, inflammation control and matrix deposition (3).

PTX3 and CRP are considered to be evolutionarily related antibodies (1). However, unlike CRP, which is induced by IL-6 and produced in the liver, PTX3 is formed locally by several cells and tissues following ligand binding to Toll-like receptors (TLR) and in response to proinflammatory signals, such as IL-1 $\beta$ and TNF- $\alpha$ (2).

There are conflicting results regarding the association between PTX3 atherogenic factors and obesity. Adipose cells produce PTX3 when stimulated by TNF- $\alpha$, although the exact function it serves in this scenario is unknown (2). Zanetti et al (4) found that PTX3 serum levels are higher in individuals with metabolic syndrome and are negatively associated with HDL cholesterol and positively associated with plasma triglyceride levels. They also found an association between PTX3 concentrations and carotid intima thickness. Lee et al (5) described an inverse association between PTX3 levels and metabolic syndrome, being overweight/obese and parameters of dyslipidemia, suggesting a potential cardioprotective role of this marker. However, animal studies showed that PTX3 deficiency reduces metabolic inflammation and prevents weight gain in mice fed with a high fat diet (6).

Although PTX3 has been largely studied in association with obesity and dyslipidemia, few studies have examined changes in PTX3 levels following bariatric surgery. Santilli et al (7) studied PTX3 levels in 12 obese patients following gastric banding, and found that PTX3 levels were low in the preoperative period and they increased following the procedure, and PTX3 levels were inversely associated with platelet activation markers. Barazzoni et al (8) found that severely obese individuals had higher than normal PTX3 levels and following Roux-en-Y gastric bypass, the levels increased further.

In the present study, PTX3 levels in a sample of obese patients who underwent bariatric surgery were measured to analyze the variability in its levels in association with weight loss and changes in patients' metabolic profile. 


\section{Patients and methods}

Patients. The present study was a prospective study and was approved by the Committee of Ethics in Research, Sociedade Evangélica Beneficente de Curitiba (Curitiba, Brazil; approval no. 2.325.452). All participants provided signed informed consent for participation. A total of 84 obese patients undergoing bariatric surgery and 94 non-obese controls without any known disease, all aged $>18$ years, were recruited for the present study. Patients were classed as obese if they had a body mass index $(\mathrm{BMI}) \geq 30 \mathrm{~kg} / \mathrm{m}^{2}$. This cohort was a convenience sample which includes all the patients who underwent bariatric surgery in a 1 year period, in two university hospitals from same geographic region and that agreed to participate in the study. In this sample $72 / 84(85.7 \%)$ were females and $12 / 84(14.2 \%)$ were males with a median age of 36 years (range, 19-63 years). Patients with chronic inflammatory diseases, a history of cancer, altered renal function and obesity secondary to endocrinopathies (such as Cushing's syndrome or hypothyroidism) were excluded. All patients underwent Roux-en-Y gastric bypass, and this was performed by the same surgical team following a multidisciplinary pre-operative evaluation by qualified clinicians in the fields of nutrition, endocrinology, cardiology and psychology. All patients underwent preoperative upper gastrointestinal endoscopy and abdominal ultrasound.

Data collection. Patients who underwent bariatric surgery were monitored for 60 days prior to the surgery and followed up in the post-operative period for 360 days. Epidemiological data regarding BMI, abdominal circumference, blood pressure, lipid profile (total cholesterol, HDL and LDL cholesterol, and triglycerides), fasting glycemia, hemoglobin A1c, basal insulin levels, uric acid, creatinine, albumin, blood cell count and transaminases were obtained at the same time as PTX3 measurements in the pre- and post-operative period.

Measurement of PTX3 levels. PTX3 levels were measured in plasma samples using a commercially available ELISA kit (XpressBio; cat. no. XPEH0263) with a detection range of $0.31-20 \mathrm{ng} / \mathrm{ml}$ and an inter-assay precision coefficient variation of $<10 \%$.

Statistical analysis. All statistical analyses were performed in GraphPad Prism version 6.01 (GraphPad Software, Inc.). Results were gathered in frequency and contingency tables. A Shapiro Wilk test was used to analyze data distribution. Comparison of nominal data was performed using a $\chi^{2}$ test, comparisons of numerical data were performed using a Wilcoxon matched-pairs signed rank test or a Student's t-test based on the distribution of the data. Comparison of PTX3 levels between patients (pre and post-operative) and controls was performed using a Kruskal-Wallis test followed by a post-hoc Dunn's test. Correlation analyses of PTX3 with the other numerical variables were performed using Spearman's Rank Correlation tests. $\mathrm{P}<0.05$ was considered to indicate a statistically significant difference.

\section{Results}

Characteristics of the recruited cohort. In the pre-operative period, $32 / 84$ patients $(38.1 \%)$ were diagnosed with

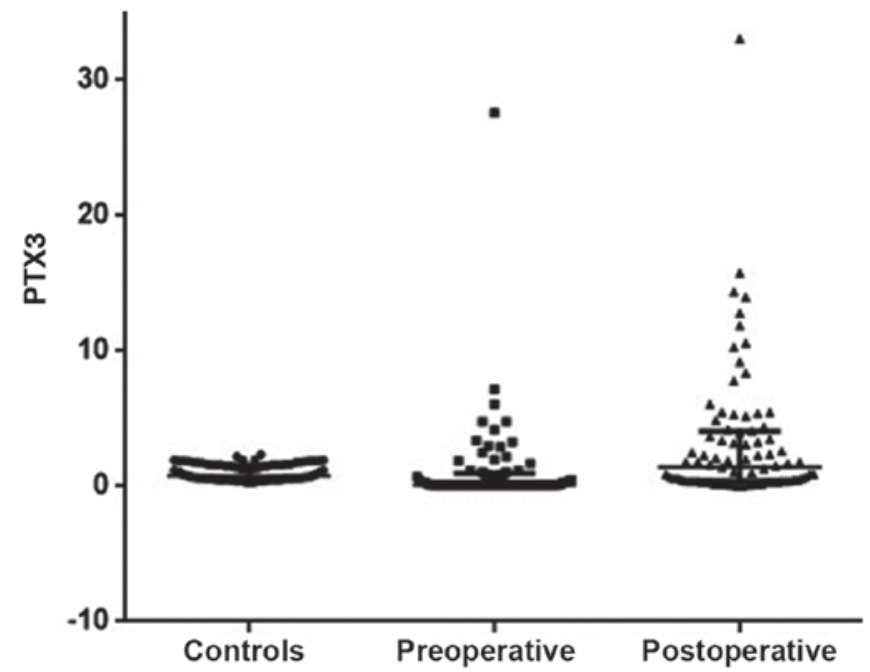

Figure 1. PTX3 serum levels in obese patients who underwent bariatric surgery and controls $(\mathrm{n}=84)$. The median PTX3 levels in the controls were $0.8 \mathrm{ng} / \mathrm{ml}$ (IQR, 0.5-1.6 ng/ml); in patients prior to surgery were $0.1 \mathrm{ng} / \mathrm{ml}$ (IQR, 0.1-0.97 ng/ml); and in patients following surgery were $1.45 \mathrm{ng} / \mathrm{ml}$ (IQR, 0.40-4.07 ng/ml). PTX3, pentraxin-3 levels; IQR, inter-quartile range.

dyslipidemia; $58 / 81$ patients $(71.6 \%)$ with hepatic steatosis; $41 / 84$ patients $(48.8 \%)$ with arterial hypertension; and $13 / 84$ patients $(15.5 \%)$ with diabetes mellitus. The post-operative evaluation was performed for between 106-375 days following surgery (mean \pm standard deviation, $217 \pm 56.7$ days) and the weight loss ranged from $14-72 \mathrm{~kg}$ with a median weight loss of $33.1 \mathrm{~kg}$. The characteristics of the patients in the pre- and post-operative period are presented in Table I.

PTX3 levels in the pre- and post-operative period. PTX3 levels in the control group and in the obese patients pre- and post-surgery are presented in Fig. 1. Comparison of PTX3 levels in pre- and post-operative patients and controls showed there was as significant difference $(\mathrm{P}<0.0001)$. The post-hoc Dunn's test showed that the PTX3 levels were significantly lower in the controls compared with the levels in the pre-operative patients, and the levels of PTX3 in the pre-operative patients were significantly lower compared with the levels in the post-operative patients (both $\mathrm{P}<0.05$ ).

The variation in PTX3 values from pre- and post-surgery had a median value of $0.55 \mathrm{ng} / \mathrm{ml}$; (inter-quartile range $=0.12-2.97 \mathrm{ng} / \mathrm{ml})$ and were not correlated with variations in BMI $(\varrho=-0.01 ; \mathrm{P}=0.91)$ or the number of days following surgery $(\mathrm{Q}=0.09 ; \mathrm{P}=0.38)$.

No differences in PTX-3 serum concentrations were observed between males and females. In the pre-operative period, male patients had a median PTX3 level of $0.20 \mathrm{ng} / \mathrm{ml}$ (range, $0.10-1.77 \mathrm{ng} / \mathrm{ml}$ ) and females had a median value of $0.10 \mathrm{ng} / \mathrm{ml}$ (range, $0.10-0.90 \mathrm{ng} / \mathrm{ml})(\mathrm{P}=0.45)$. In the post-operative period, the median value in males was $0.45 \mathrm{ng} / \mathrm{ml}$ (range, $0.20-3.50)$ and in females it was $1.55 \mathrm{ng} / \mathrm{ml}$ (range, 0.40-4.15) $(\mathrm{P}=0.18)$.

Correlation analysis of the PTX3 levels prior to surgery with clinical and metabolic variables did not show any statistical significance. Correlation analysis of the PTX3 levels following surgery with clinical and metabolic variables showed that there was significant positive correlation with 
Table I. Primary characteristics of the patients who underwent bariatric surgery.

\begin{tabular}{|c|c|c|c|}
\hline Variables & Before surgery & After surgery & P-value \\
\hline BMI $\left(\mathrm{kg} / \mathrm{m}^{2}\right)$ & & & $<0.0001^{\mathrm{d}}$ \\
\hline Range & $35.1-64.8$ & $22.4-44.5$ & \\
\hline Median (IQR) & $44.6(41.4-48.1)$ & $31.0(28.4-34.3)$ & \\
\hline Systolic BP, mm Hg & & & $<0.0001^{\mathrm{d}}$ \\
\hline Range & $90-200$ & $90-170$ & \\
\hline Median (IQR) & $125(110-140)$ & $120(110-120)$ & \\
\hline Diastolic BP, mm Hg & & & $<0.0001^{\mathrm{d}}$ \\
\hline Range & $60-110$ & $50-100$ & \\
\hline Median (IQR) & $80(70-90)$ & $70(70-80)$ & \\
\hline Abdominal circumference, $\mathrm{cm}$ & & & $<0.0001^{\mathrm{d}}$ \\
\hline Range & $102-176$ & $73-141$ & \\
\hline Median (IQR) & $126(118-137)$ & $100(93-110)$ & \\
\hline Total cholesterol, mg/dl & & & $<0.0001^{\mathrm{d}}$ \\
\hline Range & $120.0-291.0$ & $116.0-234.0$ & \\
\hline Median (IQR) & $191.7(167.4-222.0)$ & $167(139-189)$ & \\
\hline LDL cholesterol, mg/dl & & & $<0.0001^{\mathrm{d}}$ \\
\hline Range & $60-184$ & $44-146$ & \\
\hline Mean \pm SD & $118.6 \pm 29.2$ & $99.9 \pm 24.1$ & \\
\hline HDL cholesterol, mg/dl & & & 0.96 \\
\hline Range & $29.2-81.0$ & $28.7-79.0$ & \\
\hline Median (IQR) & $45.3(36.0-53.0)$ & $46.0(39.0-52.0)$ & \\
\hline Triglycerides, mg/dl & & & $<0.0001^{\mathrm{d}}$ \\
\hline Range & $68-462$ & $38-343$ & \\
\hline Median (IQR) & $135.3(101.8-178.8)$ & $94(72.5-134.0)$ & \\
\hline Fasting glucose, mg/dl & & & $0.0002^{\mathrm{c}}$ \\
\hline Range & $66-408$ & $60-137$ & \\
\hline Median (IQR) & $91(82-103)$ & $87.5(79.2-92.0)$ & \\
\hline Hemoglobin A1c, $\%$ & & & $<0.0001^{\mathrm{d}}$ \\
\hline Range & $4.7-9.9$ & $4.0-8.1$ & \\
\hline Median (IQR) & $5.4(5.2-5.9)$ & $5.2(5.0-5.6)$ & \\
\hline Basal insulin, mIU/l & & & $<0.0001^{\mathrm{d}}$ \\
\hline Range & $3.0-168.7$ & $1.6-42.4$ & \\
\hline Median (IQR) & $15.6(8.3-27.8)$ & $6.8(4.5-12.1)$ & \\
\hline Uric acid, mg/dl & & & $<0.0001^{\mathrm{d}}$ \\
\hline Range & $2.0-9.3$ & $1.9-7.2$ & \\
\hline Mean \pm SD & $4.8 \pm 1.45$ & $4.3 \pm 1.20$ & \\
\hline Ferritin, ng/ml & & & 0.10 \\
\hline Range & $7-1042$ & $9.8-697.0$ & \\
\hline Median (IQR) & $165.0(55.3-259.5)$ & $128.0(73.0-243.0)$ & \\
\hline Albumin, g/l & & & $0.02^{\mathrm{a}}$ \\
\hline Range & $3.4-4.8$ & $3.1-5.3$ & \\
\hline Median (IQR) & $4.0(3.8-4.3)$ & $4.1(4.0-5.3)$ & \\
\hline Oxalacetic transaminase, $\mathrm{U} / \mathrm{l}$ & & & 0.58 \\
\hline Range & $9-90$ & $9-52$ & \\
\hline Median (IQR) & $22.5(18.0-33.0)$ & $25(18-31)$ & \\
\hline Pyruvate transaminase, $\mathrm{U} / \mathrm{l}$ & & & 0.06 \\
\hline Range & $6-145$ & $9-79$ & \\
\hline Median (IQR) & $26.0(17.0-39.2)$ & $24(16-37)$ & \\
\hline Creatinine, mg/dl & & & 0.20 \\
\hline Range & $0.5-1.2$ & $0.5-1.2$ & \\
\hline Median (IQR) & $0.8(0.7-0.9)$ & $0.8(0.7-0.9)$ & \\
\hline
\end{tabular}


Table I. Continued.

\begin{tabular}{lcc}
\hline Variables & Before surgery & After surgery \\
\hline Hemoglobin, g/dl & & $10.6-15.9$ \\
Range & $11.4-16.6$ & $12.9(12.5-13.6)$ \\
Median (IQR) & $13.1(12.5-14.0)$ & \\
Hematocrit, $\%$ & $31.5-49.7$ & $32.5-47.6$ \\
Range & $39.9 \pm 3.41$ & $39.3 \pm 3.16$ \\
Mean $\pm \mathrm{SD}$ & & \\
Platelets, $\mathrm{n} / \mathrm{mm}^{3}$ & $127,000-474,000$ & $138,000-465,000$ \\
Range & $241,500(209,250-291,000)$ & $233,000(195,200-288,250)$ \\
Median (IQR) & & 0.19 \\
Vitamin D, ng/ml & $6.8-47$ & $9.7-52.0$ \\
Range & $25.5(18.6-29.9)$ & $28.5(24.2-33.7)$ \\
Median (IQR) & & $0.001^{\mathrm{b}}$ \\
\hline
\end{tabular}

${ }^{\mathrm{a}} \mathrm{P}<0.05,{ }^{\mathrm{b}} \mathrm{P}<0.01,{ }^{\mathrm{c}} \mathrm{P}<0.001,{ }^{\mathrm{d}} \mathrm{P}<0.0001$. IQR, inter-quartile range; $\mathrm{SD}$, standard deviation; $\mathrm{BMI}$, body mass index; $\mathrm{BP}$, blood pressure.

Table II. Correlation analysis of variability of values prior to and following bariatric surgery with the variability in pentraxin-3 levels.

\begin{tabular}{lccc}
\hline & \multicolumn{3}{c}{$95 \%$ confidence } \\
Variables & Spearman @ & $-0.26-0.17$ & 0.68 \\
\hline$\Delta$ Body mass index & -0.04 & $-0.26-0.18$ & 0.70 \\
$\Delta$ Total cholesterol & -0.04 & $-0.14-0.30$ & 0.47 \\
$\Delta$ HDL cholesterol & 0.08 & $-0.29-0.16$ & 0.55 \\
$\Delta$ Triglycerides & -0.06 & $-0.20-0.34$ & 0.59 \\
$\Delta$ Basal insulin & 0.07 & $-0.21-0.23$ & 0.53 \\
$\Delta$ Fasting glycemia & 0.008 & $-0.20-0.34$ & 0.59 \\
$\Delta$ Hemoglobin A1c & 0.007 & $-0.39-0.05$ & 0.12 \\
$\Delta$ Uric acid & -0.18 & & \\
\hline
\end{tabular}

$\Delta$, difference in.

triglyceride levels (although this correlation was modest; $\mathrm{Q}=0.26 ; 95 \% \mathrm{CI}, 0.03-0.46 ; \mathrm{P}=0.01)$. Detailed results of the correlation analyses between pre- and post-surgery PTX3 levels with other variables are presented in Table II.

\section{Discussion}

The results of the present study showed that obese patients have lower levels of PTX3 compared with non-obese patients and that bariatric surgery results in restoration of physiological levels. These results are in agreement with previous studies from Ogawa et al (9) and Osorio-Conles et al (10), who both found an inverse association between the serum blood levels of PTX3 and BMI. In addition, PTX3 serum levels are increased in obese patients who underwent dietary intervention (11) and gastric banding (7).

There was no association between PTX3 levels and the lipid profile or the glycemic controls; however, the elevation of this biomarker itself is of interest for patients undergoing bariatric surgery as it has been shown that PTX3 may exert a protective role on the cardiovasculature (12). Animal studies of PTX3 null mice demonstrated that they develop severe inflammatory changes in the vascular walls, with an increased number of macrophages in atherosclerotic plaques, suggesting that PTX3 may exert a regulatory function in vascular associated inflammation (12). In an experimental ischemia-reperfusion model of myocardial infarction, PTX3 deficient animals showed significantly larger infarcts compared with the wild-type controls, suggesting that PTX3 serves a role in myocardial damage and repair (13). PTX3 deficient animals had higher deposition of C3 (complement system) in the damaged tissue, thus it is possible that the protective function of PTX3 may transpire through prevention of tissue damage by excessive complement deposition (13). PTX3 inhibits activation of the classic complement pathway by preventing an interaction between immunoglobulins and C1q (14), and inhibits the alternate pathway by controlling the deposition of $\mathrm{H}$ factor in apoptotic cells (15).

Norata et al (16) showed that HDL-cholesterol is capable of inducing the expression of PTX3 mRNA in vascular endothelial cells. They suggested that the protective effect of HDL on atherosclerosis may partly be due to its modulation of PTX3 secretion.

Obesity is a low-grade inflammatory disease and a significant risk factor of cardiovascular morbidity (17). A study on PTX3 gene expression in cultured adipocytes found that PTX3 is upregulated locally, and that the production of this biomarker is higher in visceral adipose tissue compared with subcutaneous fat (10). However, in the same study, the blood levels of PTX3 were inversely associated with obesity and thus the authors hypothesized that local production of PXT3 regulates the equilibrium between an inflammatory and anti-inflammatory response (10). Therefore, if PTX3 exerts a protective effect against metabolic syndrome, lowering blood PTX3 levels in obese patients may lead to a reduction in the inflammatory process resulting from increased fat mass (11).

There was no association between PTX3 levels and insulin levels, glycemic controls or any of the lipid profile fractions assessed except for triglycerides following surgery. Contrasting results regarding the association between PTX3 levels and 
triglycerides have been reported. Zanetti et al (4) found a positive correlation between plasma triglyceride and PTX3 levels, whereas a negative association was observed by Lee et al (5) and Yamasaki et al (18). A possible explanation for the discrepant results may be due to small sizes in each study and the use of patients with a specific disease (11). In the present study, a modest but significant positive correlation was observed between PTX3 and triglycerides levels in the post-operative period.

The present study has some limitations: The PTX3 measurements were taken at different intervals following surgery and there was a relatively lower number of males in the experimental cohort (14.3\%). Additional studies, with a higher proportion of male patients and fixed intervals of PTX3 measurement will increase the reliability of the results and allow for stratification by sex to remove this as a potential confounding factor, thus clarifying the results further. Nevertheless, the present study does show that bariatric surgery restores PTX3 levels to physiological levels, demonstrating the beneficial effect of this type of surgery on cardiovascular risk.

In conclusion, the study showed that bariatric surgery restores PTX3 levels to physiological levels. Additional studies are required to understand the value increased PTX3 levels in obese patients on the prevention of cardiovascular.

\section{Acknowledgements}

Not applicable.

\section{Funding}

No funding was received.

\section{Availability of data and materials}

The datasets used and/or analyzed during the present study are available from the corresponding author on reasonable request.

\section{Authors' contributions}

AFT, RN, PANN and TS designed and performed the experiments. SIM, AGC and JSCG collected the patients' data and serum samples. AFT, RN and TS organized and analyzed data. All authors were involved in writing the paper and approved the final version of the manuscript.

\section{Ethics approval and consent to participate}

The present study was a prospective study and was approved by the Committee of Ethics in Research, Sociedade Evangélica Beneficente de Curitiba (Curitiba, Brazil; approval no.2.325.452). All participants provided signed informed consent for participation.

\section{Patient consent for publication}

Not applicable.

\section{Competing interests}

The authors declare that they have no competing interests.

\section{References}

1. Ristagno G, Fumagalli F, Bottazzi B, Mantovani A, Olivari D, Novelli D and Latini R: Pentraxin 3 in cardiovascular disease. Front Immunol 10: 823, 2019.

2. Balhara J, Koussih L, Zhang J and Gounni AS: Pentraxin 3: An immuno-regulator in the lungs. Front Immunol 4: 127, 2013.

3. Jaillon S, Bonavita E, Gentile S, Rubino M, Laface I, Garlanda C and Mantovani A: The long pentraxin PTX3 as a key component of humoral innate immunity and a candidate diagnostic for inflammatory diseases. Int Arch Allergy Immunol 165: 165-178, 2014.

4. Zanetti M, Bosutti A, Ferreira C, Vinci P, Biolo G, Fonda M, Valente M, Cattin L, Guarnieri G and Barazzoni R: Circulating pentraxin 3 levels are higher in metabolic syndrome with subclinical atherosclerosis: Evidence for association with atherogenic lipid profile. Clin Exp Med 9: 243-248, 2009.

5. Lee R, Ahn HR, Shin MH, Kim HN, Lee YH, Choi SW and Kweon SS: Association of plasma pentraxin-3 level with lipid levels and cardiovascular risk factors in people with no history of lipid-lowering medication: The Dong-gu Study. J Atheroscler Thromb 26: 738-745, 2019.

6. Bonacina F, Moregola A, Porte R, Baragetti A, Bonavita E, Salatin A, Grigore L, Pellegatta F, Molgora M, Sironi M, et al: Pentraxin 3 deficiency protects from the metabolic inflammation associated to diet-induced obesity. Cardiovasc Res 115: 1861-1872, 2019.

7. Santilli F, Guagnano MT, Innocenti P, Aceto L, Vazzana N, Lattanzio S, Liani R, Tripaldi R, Creato V, Romano M, et al: Pentraxin 3 and platelet activation in obese patients after gastric banding. Circ J 80: 502-511, 2016.

8. Barazzoni R, Palmisano S, Gortan Cappellari G, Giuricin M, Moretti E, Vinci P, Semolic A, Guarnieri G, Zanetti M and Manzini N: Gastric bypass-induced weight loss alters obesity-associated patterns of plasma pentraxin-3 and systemic inflammatory markers. Surg Obes Relat Dis 12: 23-32, 2016.

9. OgawaT,Kawano Y,Imamura T,Kawakita K, Sagara M, Matsuo T, Kakitsubata Y, Ishikawa T, Kitamura K, Hatakeyama K, et al: Reciprocal contribution of pentraxin 3 and C-reactive protein to obesity and metabolic syndrome. Obesity (Silver Spring) 18: 1871-1874, 2010.

10. Osorio-Conles O, Guitart M, Chacón MR, Maymo-Masip E, Moreno-Navarrete JM, Montori-Grau M, Näf S, Fernandez-Real JM, Vendrell J and Gómez-Foix AM: Plasma PTX3 protein levels inversely correlate with insulin secretion and obesity, whereas visceral adipose tissue PTX3 gene expression is increased in obesity. Am J Physiol Endocrinol Metab 301: E1254-E1261, 2011.

11. Witasp A, Carrero JJ, Michaëlsson K, Ahlström H, Kullberg J, Adamsson V, Risérus U, Larsson A, Helmersson-Karlqvist J, Lind L, et al: Inflammatory biomarker pentraxin 3 (PTX3) in relation to obesity, body fat depots and weight loss. Obesity (Silver Spring) 22: 1373-1379, 2014.

12. Norata GD, Marchesi P, Pulakazhi Venu VK, Pasqualini F, Anselmo A, Moalli F, Pizzitola I, Garlanda C, Mantovani A and Catapano AL: Deficiency of the long pentraxin PTX3 promotes vascular inflammation and atherosclerosis. Circulation 120: 699-708, 2009.

13. Salio M, Chimenti S, De Angelis N, Molla F, Maina V, Nebuloni M, Pasqualini F, Latini R, Garlanda C and Mantovani A: Cardioprotective function of the long pentraxin PTX3 in acute myocardial infarction. Circulation 117: 1055-1064, 2008.

14. Nauta AJ, Bottazzi B, Mantovani A, Salvatori G, Kishore U, Schwaeble WJ, Gingras AR, Tzima S, Vivanco F, Egido J, et al: Biochemical and functional characterization of the interaction between pentraxin 3 and C1q. Eur J Immunol 33: 465-473, 2003.

15. Erreni M, Manfredi AA, Garlanda C, Mantovani A and Rovere-Querini P: The long pentraxin PTX3: A prototypical sensor of tissue injury and a regulator of homeostasis. Immunol Rev 280: $112-125,2017$.

16. Norata GD, Marchesi P, Pirillo A, Uboldi P, Chiesa G, Maina V, Garlanda C, Mantovani A and Catapano AL: Long pentraxin 3, a key component of innate immunity, is modulated by high-density lipoproteins in endothelial cells. Arterioscler Thromb Vasc Biol 28: 925-931, 2008.

17. Garlanda C, Bottazzi B, Moalli F, Deban L, Molla F, Latini R and Mantovani A: Pentraxins and atherosclerosis: The role of PTX3. Curr Pharm Des 17: 38-46, 2011.

18. Yamasaki K, Kurimura M, Kasai T, Sagara M, Kodama T and Inoue K: Determination of physiological plasma pentraxin 3 (PTX3) levels in healthy populations. Clin Chem Lab Med 47: 471-477, 2009. 